\title{
Extending the cartographic capabilities of desktop GIS - Implementing less common statistical mapping methods as web services together with students
}

\author{
Gertrud Schaab $^{\mathrm{a}, *}$, Christian Stern ${ }^{\mathrm{a}}$ \\ ${ }^{a}$ Karlsruhe University of Applied Sciences, Faculty of Information Management and Media, Moltkestr. 30, 76133 Karlsruhe, \\ Germany,gertrud.schaab@h-ka.de,christian.stern@h-ka.de \\ * Corresponding author
}

\begin{abstract}
For various reasons statistical mapping is receiving increased interest within the technological shift towards service-oriented web cartography. At the same time new teaching approaches are required at universities which combine both, the motivating of students to get a grip on active programming while learning also about less common thematic mapping methods. The paper points to those cartographic representation methods of visualizing areal distributions of quantitative area characteristics which are often overlooked either due to not being readily available in GIS software or because they are simply not known. Of the nine methods discussed in regard to their abilities and limitations, five are not readily implemented or supported by the ArcGIS Pro software. Within the new teaching course on web processing services (WPS) as part of the International Geomatics master programme at Karlsruhe University of Applied Sciences, the students learn how to conceptualize, program and publish a WPS by gaining a solution for those less common methods. The alternate band map method serves as teaching example, but students are asked to independently work on other methods, too. The WPS course acts here as an eye-opener for the students to the wider pool of cartographic visualization options, of how to get around the limitations of GIS software, and of how to automate processes including making them available to others. With that we hope to contribute to automatically rendered thematic maps becoming more versatile again.
\end{abstract}

Keywords: thematic cartography, service-oriented web cartography, web processing service (WPS), choropleth map subtypes, areal diagrams

\section{Introduction}

Thematic cartography is gaining momentum. Global data integration and online mapping will increasingly focus on socio-economic data (Smith, 2016). Spatial data infrastructures (SDI) store already manifold data using geoportals for their visualization (Cerba \& Cepicky, 2012; Zepner et al., 2020). The open data movement includes more and more statistical data, too, driven by the aim to assess and reach the targets as set by the sustainable development goals (SDG) (Kraak et al., 2018; Wu et al., 2020). For analyzing the vastly growing big geospatial point data, intelligent visualization approaches are suggested (Coetzee \& Rautenbach, 2017; Gröbe \& Burghardt, 2017). Furthermore, the widely available and accessibly data asks for easy ways of interaction (Kraak et al., 2018). These developments explain why statistical mapping is receiving increased interest within the technological shift towards service-oriented web cartography which builds on software functionality known from desktop GIS and traditional web mapping.

To meet not only the new amount of data but also its versatility, thematic map making requires the support of diversity among visualization options (Schaab et al., 2021). At Karlsruhe University of Applied Sciences
(HKA) training students in thematic cartography has always received special attention (Schaab, 2014). However, due to the breadth of software-based technologies which are nowadays applied to geodata, training students in these diverse fields as well as in programming and software development gained importance. In order to still offer more than just the basics of thematic cartography, new approaches were sought which combine both requirements: to motivate students in getting a grip on active programming while teaching also about less common thematic mapping methods.

Based on experience gained during a workshop with students on how to use Python for coming up with a web service for the alternate band map method, a new course on web processing services (WPS) was included in the International Geomatics master study programme. Here, the students learn how to implement cartographic web services, which deliver the geometries required for designing thematic maps, for which GIS software is not readily providing. With the created features for the map face and the legend at hand, an automated visualization within a geoportal can be supported but also high-end cartographic design in desktop mapping (DTM) or in stand-alone interactive dynamic map environments based on traditional web mapping techniques. 
In the following a short summary on statistical mapping is provided (section 2), before elaborating on alternatives to the common choropleth map (section 3). In section 4 the new teaching course on setting-up web processing services is described for which we target often overlooked mapping methods. The paper is rounded off (section 5) with a discussion and conclusions.

\section{Statistical mapping}

Open statistical data on demographic and socio-economic variables is usually turned into thematic maps by applying the related administrative zone boundaries (Smith, 2016). The ease due to widely available automation routines has led to complaints that only a small number of representation forms are applied, with choropleth maps besides proportional symbol maps being most common and often the default (Schweikart \& Domnick, 2013; Roth et al., 2014; Kraak et al., 2020). Cartographic representation methods and the resulting map types are far more versatile, generally distinguishing between nine (Kraak \& Ormeling, 2010) and many more if being more specific. Table 1 lists the six methods related to statistical mapping and 17 different map types. Statistical mapping is currently mainly performed by means of GIS software or automated with the help of JavaScript and client libraries like OpenLayers, Leaflet or D3.

For sure the visualizing functionalities of GIS software have advanced a lot. However, GIS with its original focus on geodata analysis can still be limiting when making thematic maps. More often, poor maps are the results of a simplistic use of the software (Schaab et al., 2021). Table 1 provides an overview on which of the statistical map methods are supported by out-of-the-box functionality in ArcGIS Pro. While expert users, who know how to extend functionality via scripting, will be able to overcome smaller drawbacks or even create the required geometries for the reference units via overlay analysis, we argue that some of the map methods are not even known. Gaps in statistical mapping functionality in GIS software are specifically found under area-wise visualizations with the standard choropleth map being only one out of nine methods. Wu et al. (2020) point in particular to the need of disaggregating geospatial data based on demographic or socio-economic variables for a successful implementation of the SDG.

A solution to increasing the versatility of statistical mapping methods is related to the quickly evolving field of service-oriented web cartography (Krimbacher, 2014) offering functionality as software-as-a-service (SaaS). By setting-up a WPS, geometries (features) generated on request or even entire geoprocessing chains can be "shared" as input in straight-forward browser-based visualization tools of open data portals (cp. Kraak et al., 2018). Clarke et al. (2019) foresee for the future that the demands for data will be replaced by the actual use of maps with their ability to inform society and to generate knowledge. Here, more cartographic research is required to advice software developers on thematic mapping methods when implementing interactive web mapping services (Kraak et al., 2018).
Table 1: Overview on statistical mapping methods and their outof-the-box realization by means of ArcGIS Pro.

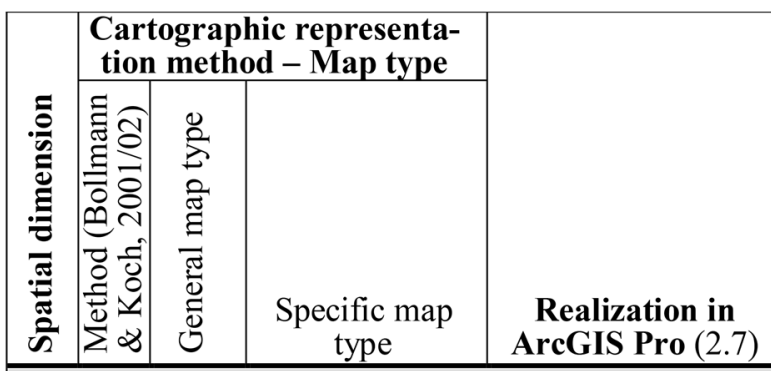

Mapping quantitative data by proportional symbols/ diagrams

\begin{tabular}{|c|c|c|c|c|}
\hline \begin{tabular}{l}
$\stackrel{0}{0}$ \\
\hdashline$\frac{0}{0}$ \\
0
\end{tabular} & 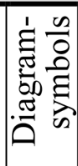 & 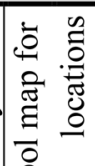 & \begin{tabular}{|l} 
Proportional \\
symbol map
\end{tabular} & $\begin{array}{l}\text { Implemented (area- } \\
\text { proportionality?) }\end{array}$ \\
\hline$\frac{\mathbb{E}}{2}$ & 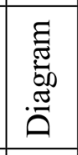 & 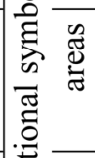 & $\begin{array}{l}\text { Diagram- } \\
\text { (metric) map } \\
\text { (chart map) }\end{array}$ & $\begin{array}{l}\text { Implemented, but } \\
\text { limited options }\end{array}$ \\
\hline & $\begin{array}{l}\stackrel{5}{0} \\
\stackrel{0}{0} \\
>\end{array}$ & : & $\begin{array}{l}\text { Flow(line) } \\
\text { map, vector } \\
\text { map }\end{array}$ & $\begin{array}{l}\text { Implemented for } \\
\text { along line features }\end{array}$ \\
\hline
\end{tabular}

Mapping scattered distributions

\begin{tabular}{|c|c|c|c|c|}
\hline 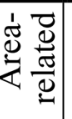 & $\overrightarrow{0}$ & 苍害 & Dot map & Not implemented \\
\hline
\end{tabular}

Mapping areal distributions

\begin{tabular}{|c|c|c|c|c|}
\hline \multirow{9}{*}{ 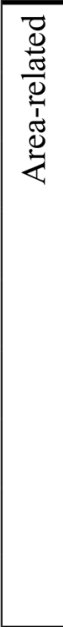 } & \multirow{9}{*}{$\begin{array}{l}\frac{5}{0} \\
\frac{0}{2} \\
\frac{0}{0} \\
0 \\
0\end{array}$} & \multirow{9}{*}{ 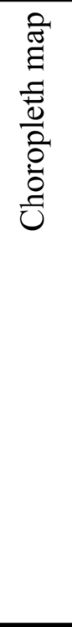 } & $\begin{array}{l}\text { Choropleth } \\
\text { map }\end{array}$ & Implemented \\
\hline & & & $\begin{array}{l}\text { Chorodot / grid } \\
\text { net map }\end{array}$ & Supported \\
\hline & & & $\begin{array}{l}\text { Dasymetric } \\
\text { map }\end{array}$ & Not implemented \\
\hline & & & $\begin{array}{l}\text { Dot density } \\
\text { map }\end{array}$ & Implemented \\
\hline & & & $\begin{array}{l}\text { Square density } \\
\text { map }\end{array}$ & Not implemented \\
\hline & & & $\begin{array}{l}\text { Absolute value } \\
\text { raster map }\end{array}$ & Not implemented \\
\hline & & & $\begin{array}{l}\text { Relative value } \\
\text { raster map }\end{array}$ & Not implemented \\
\hline & & & $\begin{array}{l}\text { Alternate band } \\
\text { map }\end{array}$ & Not implemented \\
\hline & & & $\begin{array}{l}\text { Bi-/trivariate } \\
\text { choropleth map }\end{array}$ & $\begin{array}{l}\text { Implemented (bi- } \\
\text { variate colors only) }\end{array}$ \\
\hline \multicolumn{5}{|c|}{ Mapping (statistical) surfaces } \\
\hline \multirow{4}{*}{ 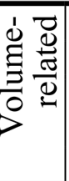 } & \multirow{4}{*}{ 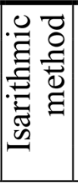 } & \multirow{4}{*}{ 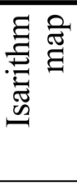 } & Isoline map & Supported \\
\hline & & & Isopleth map & Not implemented \\
\hline & & & $\begin{array}{l}\text { Volumetric } \\
\text { map }\end{array}$ & Supported \\
\hline & & & Prism map & Supported \\
\hline
\end{tabular}

\section{The less known subtypes of choropleth mapping}

Choropleth maps in the broader sense refer here to the mapping of areal distributions of quantitative area characteristics. In this paper we restrict our thoughts to those which consist of a single graphical layer only. They are typically visualized on a very limited basemap and require an equal-area projection. 


\subsection{Commonly known relative methods for different reference units}

Here, a distinction is made between choropleth vs. chorodot (grid net) vs. dasymetric maps, all applying the relative method but to different reference units (for a comparison see e.g. Imhof, 1972). They usually apply standardized data which is classified, then including the question of which method to choose, but work also unclassified, arguing for a more realistic representation. Traditionally dasymetric and chorodot maps are derived from dot maps (Kraak \& Ormeling, 2010). Nowadays the distinction between the three map types is often explained by referring to the three underlaying methods: the statistical method, spatial binning using one-shape tessellations, and dasymetric modelling.

The choropleth map in the narrower sense, i.e. as a subtype, depicts aggregated census data on demographic and socio-economic variables for reason of privacy per administrative unit. They thus give an unrealistic impression of homogeneous distribution throughout the reference units (Cockx \& Canters, 2015; Dmowska \& Stepinski, 2014). The difference in colour (or grey value) intensity denotes differences in the intensity of a phenomenon, which for non-area-related ratio maps, i.e. when the area is not accounted for in the ratio, might lead to a distorted visual impression (Kraak \& Ormeling, 2010).

A chorodot map is according to Slocum et al. (2010) a combination of the choropleth (shading assigned to each square) and the dot map (use of small squares) methods. The term grid net map may be misleading, Kraak \& Ormeling (2010) refer to the grid choropleth map instead. More generally it means the aggregating of the data into regular spatial bins such as triangles, squares, or hexagons (Battersby et al., 2017). Due to its equal-sized reference unit areas, the data does not necessarily need to be standardized. I.e. using relative values is not a must as in the other two cases.

In a dasymetric map zonal boundaries are placed where sharp/steep gradients occur in the statistical surface (Eicher \& Brewer, 2001). GIS and remote sensing facilitate generating dasymetric maps vastly by disaggregating population figures based on ancillary data (Cockx \& Canters, 2015). Different polygon (vector) and grid (raster) dasymetric methods based on areal interpolation exist (Eicher \& Brewer, 2001), with the polygon-based intelligent dasymetric modelling (Mennis \& Hultgren, 2006) being particularly known.

But what about other areal cartographic methods which allow the representation of proportions (sections) making up a topic, of spatial variation within enumeration units, of being multivariate in nature, or offering absolute and relative information at the same time? Alternative mapping methods are described in the following, for an overview see Table 2 .

\subsection{Alternative of using absolute method offering relative information at the same time}

Using the absolute method but offering relative information at the same time is possible through the dot density map method, which is more widely applied, and the square density map, which is hardly known. For an automated production of dot density maps, tools commonly place the dots randomly within the enumeration area, which can lead to misleading maps (Tyner, 2010). Another approach is to arrange the dot symbols in a regular geometric pattern throughout the enumeration units, thus avoiding by-chance distribution patterns. While the dot symbol value allows to infer absolute quantities, the various dot densities directly translate into density values of the phenomenon per enumeration unit. As pointed out by Arnberger (1997) one should consider to specify both in the legend.

Table 2: Choropleth mapping subtypes: the various approaches and options.

\begin{tabular}{|c|c|c|}
\hline & Method & Difference \\
\hline \multicolumn{3}{|c|}{ Relative method for different reference units } \\
\hline & $\begin{array}{l}\text { Choropleth } \\
\text { map }\end{array}$ & $\begin{array}{l}\text { Administrative } \\
\text { enumeration units } \\
\text { (statistical method) }\end{array}$ \\
\hline & $\begin{array}{l}\text { Chorodot / } \\
\text { Grid net map }\end{array}$ & $\begin{array}{l}\text { Geometric reference } \\
\text { units / regular net } \\
\text { (spatial binning) }\end{array}$ \\
\hline & $\begin{array}{l}\text { Dasymetric } \\
\text { map }\end{array}$ & $\begin{array}{l}\text { Geographical reference } \\
\text { units } \\
\text { (dasymetric modelling) }\end{array}$ \\
\hline \multicolumn{3}{|c|}{ Absolute method also offering relative information } \\
\hline & $\begin{array}{l}\text { Dot density } \\
\text { map }\end{array}$ & $\begin{array}{l}\text { Point symbol } \\
\text { representing a fixed } \\
\text { quantity }\end{array}$ \\
\hline 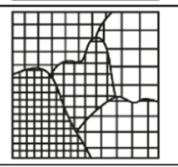 & $\begin{array}{l}\text { Square } \\
\text { density map }\end{array}$ & $\begin{array}{l}\text { Each grid cell } \\
\text { representing a fixed } \\
\text { quantity }\end{array}$ \\
\hline \multicolumn{3}{|c|}{ Revealing proportions (shares/sections) } \\
\hline & $\begin{array}{l}\text { Absolute } \\
\text { value } \\
\text { raster map }\end{array}$ & $\begin{array}{l}\text { Marking cells of overall } \\
\text { grid in their true location }\end{array}$ \\
\hline & $\begin{array}{l}\text { Relative } \\
\text { value } \\
\text { raster map }\end{array}$ & $\begin{array}{l}\text { Works with same } \\
\text { amount of grid cells per } \\
\text { reference unit }\end{array}$ \\
\hline & $\begin{array}{l}\text { Alternate } \\
\text { band map }\end{array}$ & $\begin{array}{l}\text { Slicing overall stripes } \\
\text { proportionally per } \\
\text { reference unit }\end{array}$ \\
\hline \multicolumn{3}{|c|}{ Relative method for multivariate data } \\
\hline & $\begin{array}{l}\text { Bi-/trivariate } \\
\text { choropleth } \\
\text { map }\end{array}$ & $\begin{array}{l}\text { Matrix of colours } \\
\text { combining } 2 \text { or } 3 \text { colour } \\
\text { schemes }\end{array}$ \\
\hline
\end{tabular}

Its inventor explains the square density map method (Dichtequadratmethode by F. Scharner, 1958) by approaching it from depicting unclassified dot densities, but averaged per enumeration unit, this in a regular grid fashion. 
Representing one density dot by two sides of a density square has the advantage of increasing the visual impact by more black ink and thus facilitating the distinction of even small differences. As the method works with continuously changing grid cell areas, there is no loss of information due to using categories. However, neither of the two methods reveals within-reference-unit differentiation nor proportions.

\subsection{Revealing proportions, including within-reference- unit differentiation}

Different methods can be applied for subdividing the map face according to the percentages of a variable's characteristics, to which Kraak \& Ormeling (2010) refer as areal diagrams. The absolute value raster map (Quadratraster-Flächenkartogramm by $M$. Bürgener, 1957) subdivides the entire map face by a grid of equal-sized squares. Depending on the proportions of a variable, the squares are marked by means of distinct colours always selecting grid cells as closely as possible to the category's true geographical occurrence. The optimal size of the grid cells should be chosen dependent on the map scale, the average reference unit size and the demand of depicting a given scattered distribution.

The relative value raster map works with the same amount of grid cells per enumeration unit. Thus, contrary to the absolute value raster map, each grid cell represents the same proportion throughout the entire map face and allows for more straight-forward comparison of proportions between enumeration units while delivering withinenumeration-unit distribution patterns. Achieving the basis of grid cells varying per enumeration unit, i.e. depending on its area size, used to be difficult in analog map production. The idea of such a method was also judged to be disturbing to the eye of the map reader (Arnberger, 1997).

The more common of two versions of the alternate band map method (see Poidevin, 1989 for a detailed description) covers the entire map face by stripes of equal width, which are then distinctly partitioned into slices (bands). These slices, which vary per enumeration unit, sum up to $100 \%$, thus visualizing sections of distinct categories. Within the stripes the variable's characteristics are always represented in the same order. Care has to be taken how to place the stripes. It depends on the enumeration units' sizes and shapes as well as their overall arrangement if the stripes and their slices are equally often represented (Arnberger, 1997).

\subsection{Colour mixing for bi-/trivariate choropleth maps}

So far, only univariate map methods including shares/ sections of a single variable were considered. Colour mixing is a popular option for multivariate mapping in coincident maps (Retchless \& Brewer, 2016), which results in bi- or trivariate choropleth maps. They display usually relative values of two, maximum three, quantitative variables, this simultaneously among enumeration units by creating ' $n \times n$ ' groupings where values of both variables intersect (Biesecker et al., 2020). The combined symbolization approach can illuminate relationships between data or variables (Brewer, 2006) and thus supports visual clustering or regionalization of types.

The value-by-alpha map can be considered a special case of the bivariate choropleth map, which applies transparency (via the alpha channel) per enumeration unit based on the equalizing variable. This variable refers to the quantitative attribute which indicates the significance of each enumeration unit (Gao et al., 2019) and is therefore used to generate a visual impact on the variable of interest. This is contrary to traditional bivariate choropleth maps where two variables of unknown relation are mapped deploying a two-dimensional colour space in order to explore their spatial relationship (Roth et al., 2010).

\section{Teaching web processing services}

Having elaborated on various options for areal visualization of quantitative data, next the teaching context is described which contributes to making them more known. Geomatics students need to get prepared on how to take on the chances of the ever-evolving field of information and communication technology (ICT). At the same time, they are required not to lose grip with the old but still valid, i.e. well-established, methodologies which have proven to be beneficial in data analysis and visualization. Opinions and approaches vary of how to train the future experts in the application of Python (e.g. Priyaadharshini et al., 2019) and geoprocessing services (e.g. Deng \& Di, 2008; Javed et al., 2013). Our approach for teaching Python and WPS within a single course 'Web Processing Services' in the International Geomatics master study programme aims at a versatile problem-based learning environment. The course starts with an emphasis on Python, but gradually evolves towards a focus on WPS. An introduction to the Python language and ArcPy module of the ArcGIS Platform, which allows access to its geoprocessing resources, includes small geoprocessing scripting exercises. The teaching of more advanced programming skills leads to a first assignment where each student has to come up with a different well-documented scripting tool for the ArcGIS Platform, which directly manipulates geometries. Background on OGC standards and the geoprocessing web as well as on areal representation methods for thematic maps is also provided.

For learning how to go about creating a WPS, the alternate band map method is used. Here, jointly conceptualizing the WPS is central. Having been introduced to the map method before, the students are asked to think about automating this process. It requires to break the entire process down into separate steps, for each always considering input geometries, a function, parameter(s), and output geometries. Figure 1 visualizes the concept of the geoprocessing chain via sketches of the processed geometries. As input the Alternate Bands WPS requires polygons of the enumeration units, at least two attribute fields with statistical data (allowing for up to three additional fields), the scale of the resulting map and the desired stripe width in millimetres. The angle of the stripes can be calculated automatically based on the average main orientation of all polygons if not specified. Next the centre point of the entire polygon features needs to be determined 
for rotating the geometries counterclockwise based on the 'optimal angle'. This step helps to simplify the upcoming calculations, especially when creating the slices (bands) within the stripes. Based on the minimum and maximum coordinates of the bounding box extent, stripes of a constant width are created. In the next most complex step, the stripes are split into smaller slices (bands) according to the relative values stored in the attribute table. It is performed in an iterative procedure per enumeration unit and requires an intersect with the polygon feature. Finally, the resulting geometries are rotated back based on the 'optimal angle'. Colouring of the bands is not part of the processing chain but follows suit during map design.

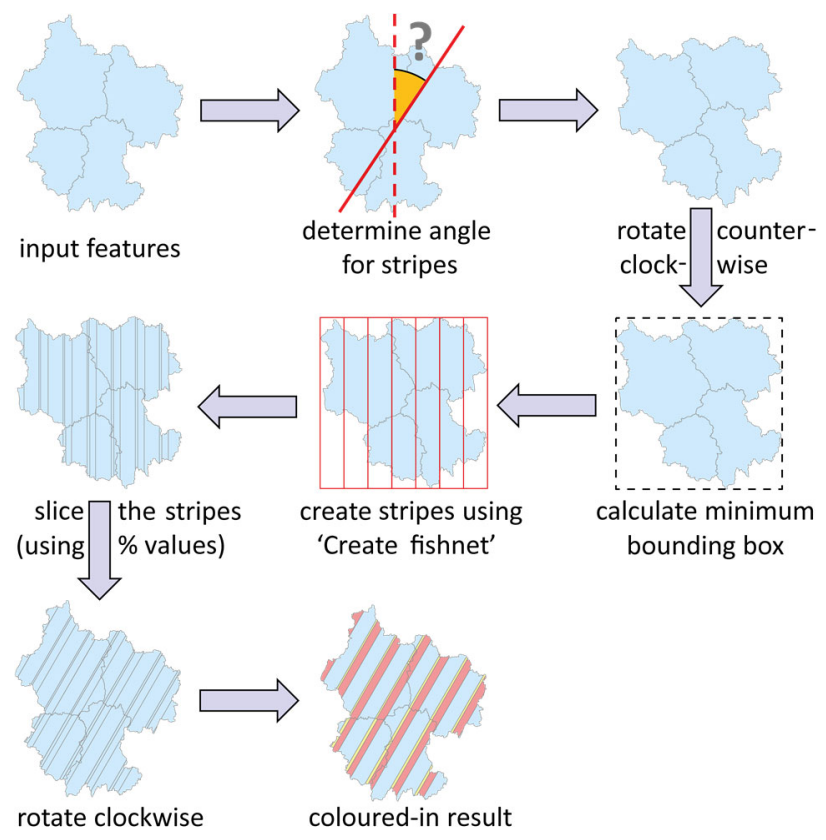

Figure 1: Conceptualizing the geoprocessing chain for the Alternate Band WPS: visualized by sketches of the processed geometries.

After the joint conceptualizing, an elaborate hands-on exercise is used to teach how the complex geoprocessing task is performed on the ArcGIS Platform. The students are handed over an incomplete model based on a ModelBuilder tool and incomplete Python scripts. Implementation requires the students to complete the code by working and getting guidance on four specific tasks and, finally, to publish the process as a WPS to ArcGIS Server. Afterwards project groups of 2 to 3 students are formed and asked now to independently realize the conceptualizing, programming and publishing of another WPS also rooted in thematic cartography. In parallel, information on WPS chaining concludes the course's learning aims. For examples of thematic cartography web services so far worked on by students see Figure 2. For a more detailed description of the entire course's setting, content and structure see Stern \& Schaab (2021).

\section{Discussion and conclusions}

We have considered here choropleth maps in the broader sense of areal depictions applying the relative method. More narrowly it can be argued that areal diagrams, too, have been included (cp. Kraak \& Ormeling, 2010). The grouping resulted from the wish to highlight areal thematic mapping methods which are less commonly used or just not known by many. In this regard we came up with a classification (Table 2), which makes their consideration more straight-forward, pointing to the map purpose and needed input data in section 3 . We thus hope to contribute to a higher versatility in map depictions again, because currently the choropleth map based on administrative units seemed to have become a standard for mapping areal distributions of quantitative data. This might have led map readers to believe that the standard choropleth method depicts statistical data best. Although tests revealed that the limitations of the method are generally not known and thus not necessarily considered when drawing conclusions from the map (Havelková \& Hanus, 2018). Its misleading emphasis on size (Besançon et al., 2020) generates a wrong visual impact of which map readers are often not aware.

Following the request by Kraak et al. (2018) to influence software developers' choices when opting for map defaults, we consider a short discussion of the other choropleth mapping subtypes useful in order to highlight their abilities and limitations. The standard choropleth map's impression of homogeneity of the densities within enumeration areas is lessened in case of the chorodot map method (Kraak \& Ormeling, 2010). With dasymetric modelling being considered a standard technique now for disaggregating census-aggregated units into raster-based data of higher spatial resolution (Dmowska \& Stepinski, 2014), the distinction between dasymetic and chorodot maps is vanishing nowadays, even more so in a slippy map viewing environment.

Dot density and square density maps convince in their capability that quantities and densities can be determined by the map reader (Arnberger, 1997). The square density method results in a visually pleasing map, in which small differences in densities are still noticeable (Scharner, 1958); i.e. it is able to depict small regional differences where they occur. However, this mapping method is hardly known and even less used.

Depending on the chosen overall grid cell size, the absolute value raster map is very good in depicting distributions, which meet the demands of visualizing minorities and majorities (Bürgener, 1957). However, the method uses the same absolute area value per grid cell throughout which leads to a different proportion depicted by a grid cell per enumeration unit as their numbers per unit vary. Therefore, comparability of square values (i.e. their proportionality) is only met within the same reference unit. This fact is visually not obvious as it is the case for the alternate band map method (Arnberger, 1997). But even small proportions $(<1 \%)$ can be visualized according to Bürgener (1957), which is in disagreement with Kraak's \& Ormeling's (2010) statement that areal diagram grid maps will always compromise the actual geographical pattern to some extent in order to render the correct proportions. Relative value raster maps are based on the same amount of grid cells per reference unit, but were considered difficult to achieve and disturbing to the eye 


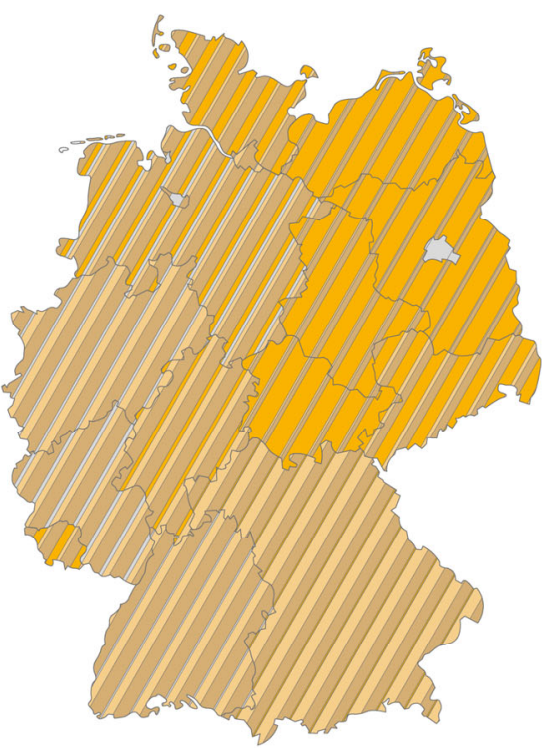

Organic farm sizes (2016)

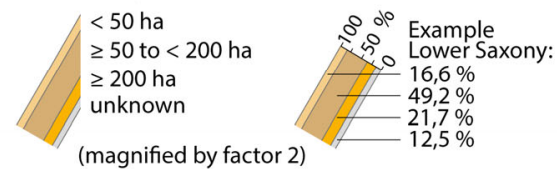

Figure 2: Example results of the cartographic web services so far automated together with students at HKA: an alternate band map (left), a square density map (centre) and an absolute value raster map (right; work in progress). The legends of the maps shown here were created using vector-graphics software. The original map sale is $3.5 \mathrm{M}$. Data sources are Destatis and Corine.

(Arnberger, 1997). The attempts described by Bürgener (1957) to achieve easily to assign multiple or partial sets of 100 grid cells to differently shaped and sized enumeration units, should nowadays not be a challenge anymore through the use of computer algorithms. However, within-reference-unit differentiation is not equally achievable throughout all enumeration units, i.e. in large-area units to a more limited extent only. The alternate band map method is limited in the number of slices per stripe, i.e. only up to five categories can be depicted (Poidevin, 1989). This method does not provide information on the actual location and spatial distribution within the reference unit (Arnberger, 1997).

Bivariate colour maps have become quite popular. However, they are limited to a small set of colours and thus attribute classes (usually three), for which in addition the selective separation between both attribute colour encodings is not straightforward (Besançon et al., 2020). Value-by-alpha maps are limited in their visualized number of classes, too. They got particularly known to counteract the false impression by choropleth representations of non-area-related ratios (Roth et al., 2010). The overview provided has highlighted the potential of eight other areal map depiction methods of quantitative data beside the standard choropleth map. It can contribute to increasing the versatility of thematic maps in geoportals and beyond and might serve also cartographic education.

The here described university course does not only cover Python and WPS programming within a single teaching course, but also service-oriented web cartography for thematic mapping. It does so by integrating theoretical knowledge of established methods (thematic cartography) and new techniques (web services), hands-on programing exercises (geoprocessing services) as well as independent programming by the students (in parts as group work). The course works closely with what the ArcGIS Platform offers. The biggest challenge encountered is the teaching of how to solve a given geoprocessing task by conceptualizing the process first (Stern \& Schaab, 2021). Not all of the less-common methods described here have been tackled yet, i.e. their realization is a still ongoing effort. Special attention needs to be directed also to serving legends (e.g. Zeng et al., 2013) in order to avoid misinterpretations of maps by the map reader (see Jenny et al., 2010; Chua \& Vande Moere, 2017). Besides, students' programming assignment work is only very sometimes done in a way that it can be directly shared with others. Instead, the WPS course acts here as an eye-opener for the students to the wider pool of cartographic visualization options, of how to get around the limitations of GIS software, and of how to automate processes including making them available to others.

Table 1 considered only which thematic cartography mapping methods can be applied straight-forward in ArcGIS Pro by guiding the map maker through wizard menus, i.e. not taking further advantage of e.g. plug-ins. The approach via wizards could be further simplified for the user by automating the map type selection procedure (cp. Tsorlini et al., 2017) which would also lead to more correct maps. Correct and likely more versatile thematic maps can be achieved in ArcGIS Pro when working with scripts (based on Arcade). However, this requires thorough cartographic training and the wish to overcome the given limitations. For extending ArcGIS functionality, Python scripting in combination with the ArcGIS ModelBuilder is 
usually used (as maybe for the Intelligent Dasymetric Toolbox for ArcGIS Pro) resulting in tools for reuse. Wrapping the tools in WPS allows their sharing as cloud services. The intention behind the teaching course is to attract attention to less-commonly applied but powerful thematic mapping methods and how to automate them in a service-oriented web cartography environment. Their availability e.g. in ArcGIS Online would tempt nontrained map makers to apply them, too. Therefore, it asks for proper documentations, while their integration in 'intelligent visualization' systems would bypass potential pitfalls by offering only those mapping methods appropriate for a given dataset (Coetzee \& Rautenbach, 2017).

Due to the automation efforts related to visualizing big data and the capabilities of nowadays interactive dynamic, web GIS-based visualization tools, we increasingly experience a mixing and interconnecting of thematic mapping methods including some of the described above (see e.g. Walker, 2017; Dmowska \& Stepinski, 2019). For regular tessellation of big geospatial point data, the huge potential for data aggregation performed on data structures has been recognized with the benefits of higher performance and implementation in spatial databases (Gröbe \& Burghardt, 2017). However, care has to be taken of the map projection. Battersby et al. (2017, p. 410) point to the resulting geometrical distortion of space as "the problem with the least scholarly discussion in [spatial] binning". Such challenges like ensuring the proper visual impact and the chance of chaining functionality, as implemented in our web services, in different ways for testing new combinations of visualization options seem attractive future activities to tackle together with our students.

To conclude, with our course on Web Processing Services we demonstrate to geomatics students that cartography nowadays still requires experts, not only regarding thematic map design in a world of increasingly available statistical data (cp. Schaab et al., 2021) but also regarding programming. They learn how WPS can be used to generate the required geometries of more complex statistical mapping methods, which are not readily available, and shared as tools to anyone interested (although in our case limited to ArcGIS users). By training the students and eventually also by making the resulting tools available we hope to contribute that automatically rendered thematic maps will become more versatile again while serving their purpose of revealing relevant geographical patterns.

\section{References}

Arnberger, E. (1997). Thematische Kartographie mit einer Kurzeinführung über EDV-gestützte Kartographie und Quellen der Fernerkundung. 4th ed., Westermann Schulbuchverlag: Braunschweig.

Battersby, S.E., Strebe, D. and Finn, M.P. (2017). Shapes on a Plane: Evaluating the Impact of Projection Distortion on Spatial Binning. Cartography and Geographic Information Science, 44(5), 410-421.
Besançon, L., Cooper, M., Ynnerman, A. and Vernier, F. (2020). An Evaluation of Visualization Methods for Population Statistics Based on Choropleth Maps. https: //arxiv.org/ftp/arxiv/papers/2005/2005.00324.pdf (accessed 13.01.2021).

Biesecker, C., Zahnd, W.E., Brandt, H.M., Adams, S.A. and Eberth, J.M. (2020). A Bivariate Mapping Tutorial for Cancer Control Resource Allocation Decisions and Interventions. Preventing Chronic Disease, 17(E01), 190254.

Bollmann, J. and Koch, W.G. (eds., 2001/02). Lexikon der Kartographie und Geomatik. 2 vol., Spektrum Akademischer Verlag: Heidelberg, Berlin.

Brewer, C.A. (2006). Basic Mapping Principles for Visualizing Cancer Data Using Geographic Information Systems (GIS). American Journal of Preventive Medicine, 30(2S), S25-S36.

Bürgener, M. (1957). Das Quadratraster-Flächenkartogramm. In: E. Meynen (ed.), Geographisches Taschenbuch. Jahrweiser zur Deutschen Landeskunde 1956/57, Franz Steiner Verlag: Wiesbaden, 466-471.

Cerba, O. and Cepicky, J. (2012). Web services for thematic maps. In: M.P. Peterson (ed.), Online maps with APIs and WebServices, Springer-Verlag: Berlin, Heidelberg, 141-155.

Chua, A. and Vande Moere, A. (2017). BinSq: Visualizing Geographic Dot Density Patterns with Gridded Maps. Cartography and Geographic Information Science, 44(5), 390-409.

Clarke, K.C., Johnson, J.M. and Trainor, T. (2019). Contemporary American Cartographic Research: A Review and Prospective. Cartography and Geographic Information Science, 46(3), 196-209.

Cockx, K. and Canters, F. (2015). Incorporating Spatial Non-stationarity to Improve Dasymetric Mapping of Population. Applied Geography, 63, 220-230.

Coetzee, S. and Rautenbach, V. (2017). A Design Pattern Approach to Cartography with Big Geospatial Data. The Cartographic Journal, 54(4), 301-312.

Deng, M. and Di, L. (2008). GeoBrain Online Resources for Supporting College-level Data-intensive Geospatial Science and Engineering Education. IGARSS 2008 proceedings, Boston (MA), 7-11 Jul 2008, IV443IV446.

Dmowska, A. and Stepinski, T.F. (2019). Racial Dot Maps Based on Dasymetrically Modeled Gridded Population Data. Social Sciences, 8, 157.

Dmowska, A. and Stepinski, T.F. (2014). High Resolution Dasymetric Model of U.S. Demographics with Application to Spatial Distribution of Racial Diversity. Applied Geography, 53, 417-426.

Eicher, C.L. and Brewer, C.A. (2001). Dasymetric Mapping and Areal Interpolation: Implementation and Evaluation. Cartography and Geographic Information Science, 28(2), 125-138. 
Gao, P., Li, Z. and Qin, Z. (2019). Usability of Value-byalpha Maps Compared to Area Cartograms and Proportional Symbol Maps. Journal of Spatial Science, 64(2), 239-255.

Gröbe, M. and Burghardt, D. (2017). Micro Diagrams: A Multi-scale Approach for Mapping Large Categorised Point Datasets. AGILE 2017 proceedings, Wageningen, 9-12 May 2017, 128.

Havelková, L. and Hanus, M. (2018). The Impact of Map Type on the Level of Student Map Skills. Cartographica, 53(3), 149-170.

Imhof, E. (1972). Thematische Kartographie. Walter de Gruyter: Berlin, New York (NY).

Javed, R., Lehmkühler, H. and Behr, F.-J. (2013). Teaching Tools for Web Processing Services. Applied Geoinformatics for Society and Environment 2013 proceedings, Ahmedabad, 16-19 Dec 2013, 399-404.

Jenny, B., Hutzler, E. and Hurni, L. (2010). Self-adjusting Legends for Proportional Symbol Maps. Cartographica, 44(4), 301-304.

Kraak, M-J. and Ormeling, F. (2010). Cartography: Visualization of Spatial Data. 3rd ed., Prentice Hall: Harlow.

Kraak, M.J., Ricker, B. and Engelhardt, Y. (2018). Challenges of Mapping Sustainable Development Goals Indicators Data. ISPRS International Journal of GeoInformation, 7, 482.

Kraak, M.-J., Roth, R.E., Ricker, B., Kagawa, A. and Le Sourd, G. (2020). Mapping for a Sustainable World. The United Nations: New York (NY).

Krimbacher, A. (2014). Service-oriented Architecture for Thematic Cartography on the Web. Master thesis, ETH Zürich, Institute of Cartography and Geoinformation. http://www.ika.ethz.ch/studium/masterarbeit/2014_krim bacher_report.pdf (accessed 22.12.2020).

Mennis, J. and Hultgren, T. (2006). Intelligent Dasymetric Mapping and Its Application to Areal Interpolation. Cartography and Geographic Information Science, 33(3), 179-194.

Poidevin, D. (1989). La Carte - Moyen d'Action. Guide Practique pour la Conception et la Réalization de Cartes. Ellipses: Paris.

Priyaadharshini, M., Natha Mayil, N., Dakshina, R., Sandhya, S. and Bettina Shirley, R. (2019). Learning Analytics: Game-based Learning for Programming Course in Higher Education. Procedia Computer Science, 172, 468-472.

Retchless, D.P. and Brewer, C.A. (2016). Guidance for Representing Uncertainty on Global Temperature Change Maps. International Journal of Climatology, 36, 11431159.

Roth, R.E., Donohue, R.G., Sack, C.M., Wallace, T.R. and Buckingham, T.M.A. (2014). A Process for Keeping Pace with Evolving Web Mapping Technologies. Cartographic Perspectives, 78, 25-49.
Roth, R.E., Woodruff, A.W. and Johnson, Z.F. (2010). Value-by-alpha Maps: An Alternative Technique to the Cartogram. The Cartographic Journal, 47(2), 130-140.

Schaab, G. (2014). Der Wandel in der KartographieAusbildung an der Hochschule Karlsruhe. Gemeinsame Tagung der DGfK, der DGPF, der GfGI und des GiN proceedings, Hamburg, 26-28 Mar 2014, 226.

Schaab, G., Adams, S. and Coetzee, S. (2021). Drawing Attention via Diversity in Thematic Map Design, as Demonstrated by Student Maps of Northern South Africa. International Journal of Cartography, DOI: 10.1080/23729333.2020.1839207.

Scharner, F. (1958). Ein Beitrag zur Frage der Dichtedarstellung in Kartogrammen. Allgemeines Statistisches Archiv, 42, 125-139.

Schweikart, J. and Domnick, I. (2013). Thematic Mapping between Individual Issue and Mass Media Product. Kartographische Nachrichten. Journal of Cartography and Geographic Information, Special Issue Juni/2013, 140-147.

Slocum, T.A., McMaster, R.B., Kessler, F.C. and Howard, H.H. (2010). Thematic Cartography and Geovisualization. 3rd ed., Pearson Prentice Hall: Upper Saddle River (NJ).

Smith, D.A. (2016). Online Interactive Thematic Mapping: Applications and Techniques for Socioeconomic Research. Computers, Environment and Urban Systems, 57, 106-117.

Stern, C. and Schaab, G. (2021). Training Students in Python Programming Skills and WPS Wrapping for Geoprocessing Tasks by Using Examples of Less Commonly Applied Thematic Mapping Methods. AGILE 2021 proceedings, 8-11 June 2021, GISS 2(15).

Tsorlini, A., Sieber, R., Hurni, L., Klauser, H. and Gloor, T. (2017). Designing a Rule-based Wizard for Visualizing Statistical Data on Thematic Maps. Cartographic Perspectives, 86, 5-23.

Tyner, J.A. (2010). Principles of Map Design. The Guilford Press: New York (NY).

Walker, K.E. (2017). Scaling the Interactive Dot Map. Cartographica, 53(3), 171-184.

Wu, B., Tian, F., Zhang, M., Zeng, H. and Zengab, Y. (2020). Cloud Services with Big Data Provide a Solution for Monitoring and Tracking Sustainable Development Goals. Geography and Sustainability, 1(1), 25-32.

Zeng, X., Du, Q., Ren, F. and Zhao, F. (2013). Design and Implementation of a Web Interactive Thematic Cartography Method Based on a Web Service Chain. Boletim de Ciências Geodésicas, 19(2), 172-190.

Zepner, L., Jirka, S., Schulte, J., Sauer, P., Darabisahneh, B., Possienka, R. and Mäs, S. (2020). Datensatz-orientierte, automatische Auswahl raum-zeitlicher Visualisierungen. Eine nutzerfreundliche und effiziente Visualisierung offener raumzeitlicher Daten der mCLOUD. https:// mviz.geo.tu-dresden.de/images/mVIZ-Leitfaden.pdf(accessed 24.02.2021). 